\title{
Atividades lúdicas, gênero e vida adulta
}

\author{
Simone Chabudee Pylro ${ }^{1}$ \\ Claudia Broetto Rossetti
}

\begin{abstract}
Resumo
Buscou-se averiguar como a preferência lúdica se evidencia na idade adulta em relação ao gênero, por meio da investigação das atividades lúdicas preferidas e praticadas por adultos jovens. Para tanto, procedeu-se à aplicação coletiva de um questionário contendo questões abertas e fechadas a 213 universitários capixabas, de ambos os gêneros, entre 21 e 40 anos. Verificou-se que pouco tempo tem sido dedicado aos jogos e brincadeiras no dia-a-dia dos participantes. As atividades preferidas foram namorar, estar com amigos, ir ao cinema, ouvir música e assistir TV. Entre as atividades tipicamente masculinas destacaram-se futebol e jogos e brincadeiras agressivas. As atividades lúdicas consideradas tipicamente femininas estão relacionadas, principalmente, a jogos simbólicos. Entre os fatores que dificultam a prática de atividades lúdicas sobressaíram-se trabalho, estudo e cansaço. Perceberam-se diferenças marcantes, segundo os gêneros, no que diz respeito às atividades lúdicas praticadas, bem como ao tempo dedicado a tais atividades.
\end{abstract}

Palavras-Chave: Adulto; Gênero; Lúdico; Lazer.

\section{Ludic activities, gender and adult life}

\begin{abstract}
The intention of this research was to investigate the favorite ludic activities carried out by young adults. The investigation employed a questionnaire, applied to 213 Capixaba university students aged between 20 and 40 years old, to find out if the differentiation in ludic preference evidences in adulthood, in function of the gender. It was verified that, on a daily basis, very little time was dedicated to games and play. The favorite activities were dating, being with friends, going to the movies, listening to music and watching TV. Amongst the men, typical activities were soccer and aggressive games and playing activities. Ludic activities considered typically female were mainly related to symbolic games. Among the reasons causing difficulties for ludic activities, the most prominent were work, study and fatigue. It was evident the notorious differences, according to gender, regarding the ludic activities performed, as well as the time dedicated to such, in function of gender.
\end{abstract}

Keywords: Adult; Gender; Ludic; Leisure.

\section{Introdução}

Uma das preocupações mais difundidas recentemente em nossa sociedade diz respeito à garantia da qualidade de vida. Esta é uma questão ampla que tem sido pensada sob vários prismas. Entre os fatores que podem contribuir para que se tenha qualidade de vida, o lazer tem sido destacado como um aspecto importante.

Entretanto, parece não ser tão simples dedicar tempo ao lazer, pois, em uma sociedade capitalista que atribui grande importância ao trabalho, constata-se que este ocupa grande parte do dia dos adultos, de maneira que o tempo livre parece ser escasso. Além disso, o tempo que sobra da atividade profissional geralmente não está tão disponível para ser empregado em atividades lúdicas. Boa parte desse tempo será destinada à capacitação, às necessidades fisiológicas diárias como comer e dormir, e aos trabalhos domésticos tais como pagar contas, arrumar e limpar a casa, cuidar dos filhos, cuidar dos animais e alimentá-los, e cumprir com obrigações familiares, sociais e religiosas - visitas oficiais, aniversários, reuniões políticas, compromissos religiosos (Dumazedier, 1976; Melo \& Alves Junior, 2003).

Quando se comparam homens e mulheres, vale ressaltar que, geralmente, nas atividades que implicam cuidados com a família, as mulheres ainda assumem uma carga significativamente maior. Segundo Dumazedier (1976, p. 28), “as horas de lazer, em todos os meios sociais, continuam a ser menos numerosas para a mulher do que para o homem".

De qualquer maneira, tornaram-se comuns, nos dias de hoje, discussões que abordam o lazer como uma atividade importante para o bem-estar do indivíduo, seja criança ou adulto. A incorporação dessas discussões pode ser verificada, segundo Melo e Alves Junior (2003, p. 1), em vários segmentos, pois,

\footnotetext{
1 Apoio à pesquisa: CNPq. Endereço para correspondência:

E-mail: chabudee@uol.com.br
} 
mesmo em jornais e revistas vemos com constância a palavra lazer, e curiosamente não mais como algo "ingênuo", discutido apenas em um caderno de futilidades ou nos cadernos de arte e cultura. O crescimento da chamada "indústria do lazer e entretenimento", uma das maiores promessas econômicas desta transição de séculos, trouxe o assunto para as páginas de negócios, rodeado de termos técnicos, números e cifras.

Falar em lazer implica pensar em temas como os jogos e as brincadeiras. Entretanto, estes podem ser considerados segmentos desse tipo de atividade, pois lazer não se encerra em tais categorias lúdicas, abrangendo também outras atividades (Dumazedier, 1976; Melo \& Alves Junior, 2003). Contudo, esta pesquisa se ocupará de questões que se referem apenas às categorias lúdicas jogos e brincadeiras.

Os comportamentos lúdicos e, especificamente, o jogo, foram estudados por historiadores, filósofos, lingüistas, antropólogos, psicólogos e educadores. A partir desses estudos, foram elaboradas teorias que apresentam concepções diversas acerca dos processos que envolvem o jogo. Pesquisas que enfocam questões acerca dos jogos e brincadeiras têm sido desenvolvidas já há algum tempo, e entre os trabalhos implementados no campo da Psicologia que destacam as atividades lúdicas, alguns têm se ocupado de levantar e discutir, seja como ponto central ou não, a preferência lúdica. Até o presente momento, a maioria dos trabalhos acerca deste tema foi realizada tomando como participantes de pesquisa crianças e adolescentes; tais estudos têm contribuído com importantes informações acerca dessa temática. Contudo, o mesmo não pode ser dito com relação à fase adulta do desenvolvimento, pois pouco se tem pesquisado acerca da preferência lúdica de adultos.

\section{Pesquisas acerca das práticas lúdicas envolvendo questões de gênero}

Maccoby (1988) sugere que a diferenciação entre gêneros, no que diz respeito a comportamentos lúdicos, deve ser considerada desde os fatores biológicos, as pressões de socialização dos adultos e a cognição. Assim, Kirkcaldy (1990) buscou relacionar gênero e determinantes de interesses recreacionais. Os dados indicaram que as mulheres demonstraram um maior interesse por jogos sociais e menor interesse por esportes de combate ou agressivos e esportes dinâmicos, enquanto os homens, por jogos de alto contato/esportes de combate, esportes de maneira geral e jogos de tabuleiro. Ainda sobre a preferência lúdica, a pesquisa realizada por Bonamigo e Koller (1993) com 28 crianças de 9 a 10 anos demonstrou que ocorrem diferenças de gênero entre meninos e meninas quanto à preferência por brinquedos. Outros estudos (Campos, Yukumitsu, Fontealba \& Bomtempo, 1994; Rossetti, 2001) com crianças e adolescentes, acerca da preferência por jogos, sugeriram que o videogame é um tipo de jogo marcadamente masculino.

Os dados apresentados por Rossetti (2001) demonstram que o tempo dedicado ao lazer pelas meninas e o tipo de lazer propriamente dito são diferentes quando comparados aos meninos, de maneira que estes teriam mais tempo para brincar. Outros estudos sobre o tema têm demonstrado que meninos preferem brincadeiras mais relacionadas a muita ação e a temas mais distantes de suas vidas cotidianas. Já as meninas preferem brincadeiras com conteúdo relacionado ao dia-a-dia (Carvalho, 1981).

Denegri e Linaza (s. d.) desenvolveram um trabalho, buscando averiguar a influência de ambientes de socialização rurais e urbanos na preferência por jogos e brinquedos, com 180 crianças e adolescentes com idades entre 6 e 15 anos. Os resultados indicaram a presença de uma seqüência evolutiva nos jogos desenvolvidos segundo idades distintas. Também puderam verificar a ocorrência de diferenças significativas quanto aos contextos sociais pesquisados, além de terem demonstrado diferenças significativas de gênero.

Ruiz (1992), em sua tese de doutorado, buscou conhecer e classificar jogos e brinquedos preferidos por estudantes de ambos os gêneros, de colégios públicos de Sevilla, com idades entre 4 e 14 anos. Em relação aos jogos preferidos, a autora pôde verificar que estes mudam com a idade. Quanto à preferência por categorias de jogos, ambos os gêneros demonstraram interesse por jogos de regras. Contudo, houve um maior interesse por parte dos meninos pelos jogos de ação, enquanto as meninas preferiram os jogos sociodramáticos. Quanto ao tipo de brinquedo, os meninos preferiram carrinho e as meninas preferiram boneca.

Souza (2000) abordou o comportamento de segregação sexual entre crianças, durante as interações lúdicas. Para tanto, desenvolveu essa pesquisa com crianças na faixa etária de 8 a 9 anos e pôde verificar, entre outras questões, que a interação dos meninos se deu de forma mais ativa e turbulenta; enquanto as meninas demonstraram níveis mais tranqüilos de interação.

Ainda sobre a preferência lúdica, Ortega et al. (1999) entrevistaram 360 crianças de ambos os gêneros, com idades variando entre 5 e 10 anos, buscando verificar a influência da idade e do gênero com relação ao tipo de jogo preferido. Foi possível, segundo os dados encontrados, verificar que o interesse pelo jogo de regras aumenta com a idade, e essa categoria de jogo foi preferida pelas crianças de ambos os gêneros. Os resultados obtidos também indicaram que a caracterização do estereótipo sexual não aumenta com a idade e 
é mais acentuada na preferência lúdica de crianças do gênero masculino. Contudo, o estudo empreendido por Ortega et al. (1999) não confirmou a preferência dos meninos por jogos de ação e a preferência das meninas por jogos simbólicos, apresentados por Ruiz (1992).

Em seu trabalho, Carvalho, Beraldo, Santos e Ortega (1993) abordam, em parte, questões semelhantes e apresentam resultados preliminares de uma pesquisa acerca dos aspectos culturais do comportamento. Segundo as autoras, os enfoques teóricos de explicações das diferentes preferências por jogos e brincadeiras variam. Algumas das possíveis origens dessas diferenciações seriam

\section{os fatores genéticos, modelação por agentes socializadores, aprendizagem espontânea de comportamentos apropriados para cada sexo, por meio de identificação com modelos do mesmo sexo. (p. 30)}

Os dados encontrados indicaram que os meninos tenderam a se mostrar mais estereotipados do que as meninas. As autoras acreditam que é possível que ocorra uma maior pressão no grupo masculino visando a uma tipificação sexual.

Verifica-se, portanto, que diversos estudos têm sido realizados privilegiando as atividades lúdicas na infância e adolescência, contudo, quando a atenção se volta para a idade adulta, algumas questões se colocam, tais como: os adultos brincam e jogam? No universo adulto ainda há espaço para os jogos e brincadeiras? Que tipo de entretenimento é mais comum entre os adultos? Será que essa diferenciação da preferência lúdica, em função do gênero, permanece na fase adulta?

Verificou-se que há escassez de trabalhos que privilegiem tais questões quando relacionadas a esta fase da vida. Portanto, a presente pesquisa teve por objetivo identificar diferentes aspectos de práticas lúdicas entre adultos jovens, tais como o lugar das atividades lúdicas nesse universo adulto, as preferências lúdicas entre adultos jovens e a existência de estereotipia sexual nas preferências por jogos e brincadeiras.

\section{Método}

\section{Participantes}

Participaram deste estudo 213 adultos jovens (Bee, 1997), na faixa etária entre 21 e 40 anos, sendo 101 do gênero masculino e 112 do gênero feminino. Entre os que responderam ao questionário, $43,7 \%$ freqüentavam aulas no turno diurno, $39,0 \%$ no noturno e $17,3 \%$ nos dois turnos. $72,3 \%$ dos participantes trabalhavam, dentre os quais, $17,0 \%$ desempenhavam suas atividades no período compreendido entre 1 e 4 horas por dia; $40,8 \%$ entre 5 e 8 horas por dia e 13,1\% trabalhavam entre 9 e 12 horas por dia.

Psico-USF, v. 10, n. 1, p. 77-86, jan./jun. 2005
Todos os participantes da pesquisa estavam matriculados em disciplinas oferecidas pelo curso de Psicologia da Universidade Federal do Espírito Santo (UFES) aos seguintes cursos de graduação: Administração (6), Biblioteconomia (25), Ciências Contábeis (12), Ciências Sociais (8), Comunicação Social (34), Educação Artística/ Artes Visuais (2), Educação Física (13), Enfermagem (5), Filosofia (4), Física (11), Geografia (8), História (9), Letras (31), Matemática (8), Música (5), Odontologia (2), Pedagogia (16), Serviço Social (13), Química (1).

O número total de estudantes matriculados na UFES no período correspondente à coleta de dados era de aproximadamente 11.500 alunos. Foram aplicados aproximadamente 500 questionários, dos quais 213 foram analisados. Vários questionários foram descartados por estar muito incompletos ou por não se enquadrar na proposta da pesquisa quanto à idade.

\section{Instrumento}

Os dados foram coletados por meio de um questionário contendo questões abertas e fechadas que buscam evidenciar opiniões acerca da prática, da preferência e da cultura lúdica de adultos. Esse questionário foi parcialmente inspirado no roteiro de entrevista utilizado por Rossetti (2001) em sua tese de doutorado. A primeira parte é composta por 26 questões abertas que buscam introduzir o tema a ser desenvolvido ao longo do questionário e elucidar algumas questões acerca das diferenças de gênero nas práticas lúdicas, segundo a perspectiva do participante. A segunda parte se constitui de uma lista com 27 itens de entretenimento que buscam verificar atividades preferidas por adultos. No presente artigo, foi privilegiada a apresentação e a discussão das questões que se referem mais especificamente às questões de gênero.

\section{Procedimento}

A aplicação dos questionários foi coletiva e ocorreu nas salas de aula da UFES, em horários cedidos pelos professores. Após as devidas orientações, os participantes responderam individualmente ao questionário, sem horário predeterminado para o término. Entretanto, a duração média de aplicação foi de 40 minutos. A pesquisadora esteve presente por todo o período em que se respondeu aos questionários. A estratégia metodológica de aplicação dos questionários em turmas de alunos matriculados em disciplinas oferecidas pelos departamentos de Psicologia a outros cursos viabilizou a inserção de alunos de diferentes áreas de conhecimento, dos turnos diurno e noturno, que trabalhavam ou não. Todos os questionários foram aplicados no horário de aula dos alunos, com prévia autorização dos respondentes e de seus respectivos professores. 
Os critérios que serviram como base para a categorização das respostas foram pensados tomando por base um estudo piloto realizado com o instrumento e a categorização efetuada por Rossetti (2001).

\section{Resultados e discussão}

Os resultados obtidos foram tabulados e tratados utilizando-se o software Statistical Package for the Social Sciences (SPSS), por meio do qual foi possível correlacionar variáveis tais como gênero e atividades lúdicas preferidas. Foram utilizados os testes qui-quadrado e o exato de Fischer para comparar diferenças nos percentuais entre as variáveis, fixando-se um nível de significância em 0,05 ou $5 \%$.

Dessa maneira, buscou-se investigar com quais atividades os adultos jovens participantes desta pesquisa se ocupam nas horas de folga. Estas atividades puderam ser agrupadas em categorias, de maneira que as mais freqüentes foram "dedica-se a atividades culturais"; "assiste à TV/a filme"; "dedica-se ao relacionamento interpessoal"; "passeia/faz lazer fora de casa". Na categoria "dedica-se a atividades culturais", foram incluídas respostas tais como: leitura, atividades relativas à música, ao cinema, ao teatro e atividades relacionadas à arte de maneira mais geral como artesanato e trabalhos manuais. Esta categoria apresentou um percentual geral para homens e mulheres de $67,9 \%$. Entre os participantes, $53,3 \%$ fizeram alusão a assistir à televisão. Este dado coincide com pesquisas realizadas com crianças e adolescentes que indicam a televisão como uma atividade de lazer cada vez mais predominante no cotidiano. Em sua pesquisa com crianças e adolescentes, Rossetti (2001) chama a atenção para o fato de que assistir à televisão já sobressai entre as atividades "não-vitais", rotineiras, assim como no estudo realizado por Mergen (1991) com adolescentes. O destaque da televisão como entretenimento comum e freqüente em quase todas as culturas também foi discutido por Dumazedier (1976).

Dos participantes que responderam sobre as ocupações das horas de folga, 46,7\% incluíram em suas respostas atividades em que dedicam algum tempo ao relacionamento interpessoal. Nesta categoria foram incluídas atividades que enfatizavam a presença dos familiares, namorados e amigos. Dessa maneira, nesta categoria, o foco maior eram as pessoas. Foram citados, por exemplo, estar/sair/conversar com amigos e familiares, namorar, brincar com filhos, entre outros. A categoria "passeia/faz lazer fora de casa" abrangeu atividades que não puderam ser inseridas em outras categorias e que indicavam a necessidade de se dirigir para fora de casa, a fim de, por exemplo, ir à praia, dar passeios curtos nas imediações da residência e viajar.

Ainda quanto ao tipo de entretenimento praticado nas horas de folga, 13,2\% dos respondentes relataram atividades tais como a prática de jogos de regras e jogos eletrônicos. Este dado indicou certa diferenciação quanto ao gênero dos participantes, pois, destes, apenas 10,7\% eram mulheres, o que sugere que há associação entre esta categoria e o gênero masculino $(p<0,001)$. Portanto, o número de homens que citou práticas de jogos de regras e jogos eletrônicos foi significativamente maior. Outros estudos demonstraram que a preferência por jogos eletrônicos já é distinta, quanto ao gênero, nas crianças e adolescentes denotando indícios de preferência por essa atividade por parte do gênero masculino (Bonamigo \& Koller, 1993; Campos, Yukumitsu, Fontealba \& Bomtempo, 1994; Rossetti, 2001).

A categoria "internet/computador" também foi mais citada por participantes do gênero masculino. Entretanto, o teste estatístico, com relação ao nível de significância estabelecido, não apresentou índice relevante, ainda que tenha obtido um valor aproximado. $\mathrm{O}$ interesse em realizar passeios fora de casa apareceu mais associado ao gênero feminino $(p<0,05)$, o que também pôde ser verificado por Rossetti (2001). A referência a esses passeios apareceu vinculada à presença de familiares, namorados e amigos. Essa escolha já se evidencia na infância e é provável que aspectos culturais relacionados à criação das meninas tenham influência nesta preferência.

Os entrevistados responderam a algumas perguntas que visavam investigar se existe estereotipia quanto aos jogos e brincadeiras vistos como femininos e masculinos. Estes dados mantêm estreita relação com os papéis sexuais introjetados por esses indivíduos, de maneira que expressaram o que acreditam ser próprio à mulher e próprio ao homem. Dados referentes a essas questões podem ser observados nas tabelas a seguir. 
Tabela 1 - Freqüência e porcentagem de respostas: jogos e brincadeiras citados como tipicamente masculinos

\begin{tabular}{lcccccc}
\hline \multicolumn{1}{c}{ Categorias } & \multicolumn{2}{c}{ Total } & \multicolumn{2}{c}{ Masculino } & \multicolumn{2}{c}{ Feminino } \\
& № & $\%$ & № & $\%$ & oo & $\%$ \\
\hline Jogo/brincadeira de azar & 1 & 1,1 & 1 & 100,0 & 0 & 0 \\
Jogo/brincadeira conteúdo sexual & 8 & 9,2 & 6 & 75,0 & 2 & 25,0 \\
Jogo/brincadeira/esportes de impacto & 22 & 25,3 & 12 & 54,5 & 10 & 45,5 \\
ou risco/violento & 2 & 2,3 & 1 & 50,0 & 1 & 50,0 \\
Jogo/brincadeira com bebida alcoólica & 2 & 2,3 & 0 & 0 & 2 & 100,0 \\
Jogo eletrônico/computador & 11 & 12,6 & 5 & 45,5 & 6 & 54,5 \\
Jogo de tabuleiro/mesa & 54 & 62,1 & 24 & 44,4 & 30 & 55,6 \\
Jogo/brincadeira esportivo & 20 & 23,0 & 11 & 55,0 & 9 & 45,0 \\
Jogo/brincadeira infantilizado & 7 & 8,0 & 6 & 85,7 & 1 & 14,3 \\
Outro & 87 & 100,0 & 44 & 50,6 & 43 & 49,4 \\
Total & & & & & &
\end{tabular}

Quanto às atividades lúdicas atribuídas ao gênero masculino, as categorias de jogos e brincadeiras citados como tipicamente masculinos que apresentaram maior índice foram "jogos e brincadeiras esportivos" (62,1\%), "jogos, brincadeiras e esportes de impacto e risco ou violentos" (25,3\%), "jogos e brincadeiras infantilizados" (23,0\%).

Na categoria "jogos e brincadeiras esportivos", o nome de jogo mais citado por ambos os gêneros, como tipicamente masculino, foi o futebol. A grande maioria das modalidades esportivas incluídas na categoria "jogos e brincadeiras esportivos" corresponde a "jogos de regras em espaços abertos". Resultados semelhantes foram encontrados por Denegri e Linaza (s. d.). Os referidos autores observaram diferenças significativas entre os gêneros, em ambos os meios, quanto à preferência por "jogos de regras em espaços abertos".

Logo após os "jogos e brincadeiras esportivos", a categoria "jogos, brincadeiras e esportes mais agressivos", que necessitam de empreendimento de força, também foi citada como a de jogos mais masculinos. Esses dados indicam, assim como Carvalho (1981) e Ruiz (1992), que as brincadeiras dos meninos envolvem muita ação, bem como a pesquisa de Souza (2000), que demonstrou diferenças no tipo de interação dos meninos e das meninas. Os meninos interagiram de forma mais ativa e turbulenta, enquanto as meninas evidenciaram formas mais tranqüilas de interação. Dessa maneira, os jogos relacionados pelos participantes como masculinos correspondem, predominantemente, a jogos de regras, e entre esses há um predomínio dos jogos praticados em espaços abertos. Na categoria "jogos e brincadeiras esportivos", o jogo mais citado por ambos os gêneros, como tipicamente masculino, foi o futebol.

$\mathrm{Na}$ pesquisa desenvolvida por Carvalho, Beraldo, Santos e Ortega (1993) com crianças, o futebol e a lutinha apresentaram estereotipia masculina forte. A comparação dos dados encontrados em pesquisas com crianças e adolescentes e os dados encontrados nesta pesquisa com adultos sugerem que ocorra na idade adulta certa manutenção dos níveis de estereotipia encontrados na infância.

A categoria "jogos/ brincadeiras infantilizados" somou um total de 23,0\%. Esta categoria englobou atividades lúdicas que são comumente dirigidas a crianças, tais como pião, carrinho, pique, pipa, entre outras. Sabe-se que essas atividades, dependendo da região e do contexto, também são praticadas por adultos, e, em alguns casos, até com certa freqüência. Contudo, parecem estar mais presentes no universo infantil. É possível que tenham sido citadas, considerando-se o período da infância, pois durante a aplicação dos questionários ocorreram perguntas por parte dos participantes acerca do período de desenvolvimento a ser considerado ao darem as respostas. A pesquisadora não direcionou a resposta dos participantes e orientou que respondessem conforme o que haviam entendido da pergunta. Esse fato pode apontar para a dificuldade de alguns em pensarem questões referentes aos jogos e brincadeiras considerando o universo adulto.

Quanto às atividades lúdicas tipicamente femininas, a categoria que apresentou maior freqüência foi "jogos/brincadeiras infantilizados". Nesta categoria foram incluídas atividades, tais como: boneca, casinha, cozinhado, panelinha, pulo em elástico, entre outras. Entre essas atividades, boneca e casinha foram as mais citadas, tanto por homens quanto por mulheres. Em sua maioria, essas são atividades ou brincadeiras de faz-de-conta que podem ser classificadas como jogos simbólicos. Segundo Ruiz (1992), este é um jogo que tem a maioria absoluta de seus adeptos entre as meninas. 
Tabela 2 - Freqüência e porcentagem de respostas: jogos e brincadeiras citados como tipicamente femininos

\begin{tabular}{|c|c|c|c|c|c|c|}
\hline \multirow{3}{*}{ Categorias } & \multirow{2}{*}{\multicolumn{2}{|c|}{ Total }} & \multicolumn{4}{|c|}{ Sexo } \\
\hline & & & \multicolumn{2}{|c|}{ Masculino } & \multicolumn{2}{|c|}{ Feminino } \\
\hline & № & $\%$ & № & $\%$ & № & $\%$ \\
\hline Jogos/brincadeiras conteúdo sexual & 5 & 6,3 & 5 & 100,0 & 0 & 0 \\
\hline Modalidades esportivas & 5 & 6,3 & 3 & 60,0 & 2 & 40,0 \\
\hline Jogos eletrônicos/computador & 2 & 2,5 & 1 & 50,0 & 1 & 50,0 \\
\hline Jogos/brincadeiras infantilizados & 55 & 68,8 & 29 & 52,7 & 26 & 47,3 \\
\hline Jogos/brincadeiras ligados à maternidade & 3 & 3,8 & 2 & 66,7 & 1 & 33,3 \\
\hline Outro & 14 & 17,5 & 7 & 50,0 & 7 & 50,0 \\
\hline Total & 80 & 100,0 & 44 & 55,0 & 36 & 45,0 \\
\hline
\end{tabular}

Mesmo que sejam evidentes as correlações entre os dados encontrados nos grupos femininos de crianças e adolescentes e no de adultos, é difícil afirmar quais fatores contribuíram para esses jogos ou brincadeiras terem sido mais citados para o gênero feminino. Pode ser que algumas circunstâncias e os papéis vividos pela mulher na sociedade brasileira contribuam para maior ênfase na prática de tais categorias de atividades lúdicas. Essa situação pode ser exemplificada na dinâmica dos cuidados com os filhos. Ainda que a participação masculina seja maior nos dias atuais, se comparada com a de décadas anteriores, a mulher continua sendo mais solicitada, até mesmo no que diz respeito à participação efetiva nos jogos e brincadeiras com os filhos, brincadeiras estas que poderiam ser classificadas como simbólicas ou sociodramáticas. Certamente essas reflexões não são conclusivas e há a necessidade de uma investigação mais precisa dos fatores que influenciaram ou determinaram um alto índice dos "jogos/brincadeiras infantilizados", no caso das mulheres adultas, nesta questão.

Os homens manifestaram maior interesse por jogos de alto contato/esportes de combate, esportes de maneira geral e jogos de tabuleiro, corroborando os dados encontrados por Kirkcaldy (1990). Dessa maneira, os dados apontam para um predomínio de jogos e brincadeiras de ação no grupo masculino e de jogos simbólicos no grupo feminino.

Uma questão que tem sido discutida no que diz respeito às diferenças de gênero é a de que a estereotipia diminuiria com a idade (Ortega et al., 1999). Entretanto, os dados apresentados na presente pesquisa indicam que essa estereotipia ainda se manifesta na idade adulta, o que sugere a necessidade de estudos que busquem verificar com maior clareza tal questão. Mesmo porque, parece evidente a influência do adulto nas preferências lúdicas de crianças com as quais estabelece vínculos afetivos significativos. Portanto, a estereotipia lúdica presente na infância parece estar atrelada a vários fatores, entre eles, a influência dos traços de estereotipia que o adulto apresenta em seu comportamento no contato com essas crianças.

Buscando-se retomar o tema do lugar das atividades lúdicas na vida dos adultos jovens, foi solicitado a cada indivíduo que descrevesse duas situações específicas. A primeira, um dia de semana típico de sua vida. E a segunda, um dia de domingo típico de sua vida. Essas questões foram apresentadas com o objetivo de expor de maneira mais clara e fiel como os adultos jovens efetivamente dispõem do tempo em seu dia-adia. Dados referentes a elas podem ser observados nas Tabelas 3 e 4.

Com relação a "um dia de semana típico", pôde-se verificar que as categorias mais relatadas pelos participantes dizem respeito à capacitação profissional ou efetivamente ao trabalho. As atividades lúdicas quase não aparecem. Dessa maneira, fica evidente nesses dados o pouco espaço de tempo dedicado ao lúdico no dia-a-dia dos participantes. Como discutido anteriormente, as atividades vinculadas ao mundo do trabalho parecem assumir uma posição de centralidade na idade adulta, de maneira que o estudo e o trabalho são considerados essenciais, sobrando pouco tempo realmente livre. De fato, autores como Melo e Alves Junior (2003) e Dumazedier (1976) afirmam que o tempo fora do local de trabalho não é tão livre, pois outras necessidades e obrigações precisam ser contempladas.

Foi possível observar que as mulheres se referiram aos cuidados que elas efetivamente dispensam à casa e aos filhos (fazer tarefas domésticas/obrigações), enquanto os homens mencionaram poucas vezes atividades desta natureza. Mais uma vez esses dados nos reportam aos encontrados por Rossetti (2001), segundo os quais as meninas, seguindo um modelo tradicional de educação, se ocupavam mais das tarefas domésticas, enquanto os meninos tinham maior disponibilidade para brincar. Dados similares também foram verificados por Dumazedier (1976). Ele afirma que as mulheres dispõem de menos horas para o lazer. 
Tabela 3 - Freqüência e porcentagem de respostas: um dia de semana típico

\begin{tabular}{lcccccc}
\hline \multicolumn{1}{c}{ Categoria } & \multicolumn{2}{c}{ Total } & \multicolumn{2}{c}{ Sexo } \\
& \multicolumn{2}{c}{ Masculino } & \multicolumn{2}{c}{ Feminino } \\
& No & $\%$ & No & $\%$ & No & $\%$ \\
\hline Ver tv/filme & 43 & 20,8 & 19 & 44,2 & 24 & 55,8 \\
Praticar jogos de regras/jogos eletrônicos & 2 & 1,0 & 2 & 100,0 & 0 & 0 \\
Praticar atividade física & 20 & 9,7 & 14 & 70,0 & 6 & 30,0 \\
Dedicar-se ao relacionamento interpessoal & 16 & 7,7 & 5 & 31,3 & 11 & 68,8 \\
Descansar/dormir & 13 & 6,3 & 7 & 53,8 & 6 & 46,2 \\
Dedicar-se a atividades culturais & 3 & 1,4 & 2 & 66,7 & 1 & 33,3 \\
Fazer tarefas domésticas/obrigações & 23 & 11,1 & 3 & 13,0 & 20 & 87,0 \\
Internet/computador & 6 & 2,9 & 3 & 50,0 & 3 & 50,0 \\
Estudar/fazer cursos/ler & 207 & 100,0 & 98 & 47,3 & 109 & 52,7 \\
Trabalhar/estagiar & 148 & 71,5 & 73 & 49,3 & 75 & 50,7 \\
Ir à Igreja/orar & 8 & 3,9 & 4 & 50,0 & 4 & 50,0 \\
Outro & 2 & 1,0 & 2 & 100,0 & 0 & 0 \\
Total & 207 & 100,0 & 98 & 47,3 & 109 & 52,7 \\
\hline
\end{tabular}

Buscando verificar se haveria um aumento na concentração das chamadas atividades lúdicas em um típico dia de folga, solicitou-se aos participantes que descrevessem um dia de domingo típico.

Tabela 4 - Freqüência e porcentagem de respostas: um dia de domingo típico

\begin{tabular}{lcccccc}
\hline \multicolumn{1}{c}{ Categoria } & \multicolumn{2}{c}{ Total } & \multicolumn{2}{c}{ Sexo } \\
& \multicolumn{2}{c}{ Masculino } & \multicolumn{2}{c}{ Feminino } \\
& No & $\%$ & № & $\%$ & o & \% \\
\hline Ver tv/filme & 109 & 52,2 & 60 & 55,0 & 49 & 45,0 \\
Praticar jogos de regras/jogos eletrônicos & 8 & 3,8 & 7 & 87,5 & 1 & 12,5 \\
Praticar exercícios físicos & 16 & 7,7 & 9 & 56,3 & 7 & 43,8 \\
Dedicar-se ao relacionamento interpessoal & 106 & 50,7 & 42 & 39,6 & 64 & 60,4 \\
Descansar/dormir/acordar mais tarde & 131 & 62,7 & 61 & 46,6 & 70 & 53,4 \\
Dedicar-se a atividades culturais & 34 & 16,3 & 18 & 52,9 & 16 & 47,1 \\
Passear/ter lazer fora de casa & 87 & 41,6 & 35 & 40,2 & 52 & 59,8 \\
Fazer tarefas domésticas/obrigações & 36 & 17,2 & 6 & 16,7 & 30 & 83,3 \\
Internet/computador & 14 & 6,7 & 6 & 42,9 & 8 & 57,1 \\
Estudar & 46 & 22,0 & 21 & 45,7 & 25 & 54,3 \\
Ler & 34 & 16,3 & 17 & 50,0 & 17 & 50,0 \\
Trabalhar & 11 & 5,3 & 5 & 45,5 & 6 & 54,5 \\
Ir à igreja/orar & 82 & 39,2 & 36 & 43,9 & 46 & 56,1 \\
Outro & 20 & 9,6 & 11 & 55,0 & 9 & 45,0 \\
Total & 209 & 100,0 & 99 & 47,4 & 110 & 52,6 \\
\hline
\end{tabular}

Conforme Dumazedier (1976), o lazer assume três funções: descanso, divertimento/recreação/entretenimento e desenvolvimento. De maneira geral, percebese a presença de tais funções no conjunto de respostas, entretanto, a preferência por "dedicar-se ao relacionamento interpessoal" também apareceu com índices significativos, principalmente para o grupo feminino. Foram reunidas nesta categoria atividades tais como: estar com amigos, namorar e estar com a família.

Segundo Ariès (1981), as atividades lúdicas tiveram, durante muito tempo, estreita relação com essa Psico-USF, v. 10, n. 1, p. 77-86, jan./jun. 2005 questão e cooperavam no sentido de fortalecer e estreitar as relações sociais. Com as transformações decorrentes de mudanças na organização da sociedade contemporânea, as atividades lúdicas, pelo menos no caso dos adultos, parecem já não ter tanta participação em tais questões como em épocas passadas. Portanto, outras atividades como, por exemplo, sair com os amigos e familiares ou namorados para "bater papo" em um bar ou restaurante apareceram como facilitadoras no sentido de maior interação social. Dessa maneira, o domingo geralmente representa um típico dia reservado ao descanso e 
à recreação, visto que a maioria das pessoas que trabalham ou estudam têm sua folga semanal nesse dia da semana.

As atividades de entretenimento são praticadas, sobretudo, nos fins de semana. Mas os dados obtidos indicam certo empobrecimento no que diz respeito à prática de jogos e brincadeiras mesmo nesses dias. Entre as atividades relatadas, houve um predomínio de dormir/ descansar/acordar mais tarde. A atividade mais citada foi ver TV/filme (52,2\%), seguido de passear $(41,6 \%)$ e ir à igreja/orar (39,2\%). A maioria dos participantes parece fazer da televisão sua principal fonte de lazer. As idas à igreja são mencionadas por ambos os gêneros e crescem aos domingos, de modo que continuam tradicionalmente fazendo parte das atividades ditas domingueiras.

As referências a jogos e brincadeiras foram poucas e, quando apareceram, referiram-se à prática de jogos de regras/eletrônicos e internet/computador. Esses dados vão ao encontro da teoria piagetiana que afirma que há um predomínio da prática de jogos de regras a partir do período operatório concreto, que se estenderia até a idade adulta. Entre os jogos e brincadeiras citados como preferidos, os jogos de regras apareceram com maior freqüência: futebol $(28,0 \%)$, baralho $(13,6 \%)$ e vôlei $(10,6 \%)$.

Os jogos e brincadeiras apontados como preferidos pelos respondentes foram categorizados, de maneira que a categoria "modalidades esportivas/jogos de quadra" foi a de maior índice, seguida por "jogos de tabuleiro/ mesa". As referências ao futebol foram decisivas para um índice alto na categoria "modalidades esportivas/jogos de quadra", considerando que esse esporte foi mencionado 37 vezes. Também vale ressaltar que os jogos eletrônicos foram mais mencionados pelos homens.

Ao citar o jogo/brincadeira preferido, nenhum dos participantes mencionou atividades mais violentas ou de combate. Em sua pesquisa, Kirkcaldy (1990) também apontou para a baixa popularidade de atividades de alto contato corporal, tais como boxe, caratê e judô. Entre os respondentes que disseram não ter um jogo preferido, $74,1 \%$ eram mulheres. Seria interessante investigar melhor a razão que levou as mulheres a mencionarem que não têm um jogo/brincadeira preferido. Quanto ao "jogo/ brincadeira preferido", o futebol foi o mais mencionado pelos homens, e baralho pelas mulheres.

As justificativas apresentadas pelos participantes quando inquiridos acerca de "por que você gosta desse jogo ou brincadeira?" tenderam a apontar alguma "utilidade" no jogo ou na brincadeira, como desenvolver habilidades, favorecer interação, exercitar, entre outras. A justificativa que mais apareceu refere-se à possibilidade do jogo/brincadeira "desenvolver ou requerer o exercício de habilidades específicas" (25,9\%). É importante ressaltar que, nessa perspectiva, o brincar/jogar aparece associado a um objetivo e um ganho calculado. Essa justificativa coincide com o discurso atual de que os jogos/brincadeiras podem ser de grande utilidade, seja como recurso pedagógico, favorecendo a interação aluno x objeto de conhecimento, seja como um meio de favorecer a interação em equipe em contextos variados ou de reproduzir situações-problema que podem favorecer o desempenho em atividades do dia-a-dia. Entretanto, também foi justificada a preferência tendo em vista a diversão pura - sem um objetivo "sério". De acordo com a literatura acerca do tema, esta seria uma perspectiva mais apropriada à definição de brincadeira.

Quase todos os participantes que disseram não gostar de jogar/brincar justificaram tal afirmação. Entre os motivos alegados, o mais citado foi que jogar seria "desnecessário". Talvez essa justificativa reflita o fato de que jogar/brincar continua sendo visto como uma atividade dispensável à vida adulta.

A atividade de maior preferência por homens e mulheres foi namorar. Segundo Macedo, Petty e Passos (1997), outros tipos de jogos mais complexos se evidenciam na vida adulta. $\mathrm{O}$ namoro poderia ser pensado como um tipo de jogo característico dessa fase. Essa perspectiva é inclusive expressa na fala de alguns participantes da pesquisa, quando indicam "jogos/brincadeiras tipicamente de adultos", como, por exemplo, "jogos sexuais", "brincadeiras de cunho sexual", "sexo", "namorar", "jogos eróticos".

As dez atividades mais citadas, segundo a ordem de maior preferência, foram: namorar, ir ao cinema, sair com amigos, ouvir música, conversar com amigos, ver TV, viajar, ir à igreja, estudar, sair com a família. Boa parte dessas atividades é, geralmente, praticada "fora de casa". De fato, os dados encontrados na investigação feita por Kirkcaldy (1990) também indicaram assistir a filmes e conversar em grupo como atividades preferidas pelos adultos participantes da referida pesquisa.

É importante mencionar que, segundo a ordem de preferência dos respondentes, os jogos não apareceram entre as dez primeiras. Este é um fato interessante se considerar-se que, na lista dos 27 itens apresentados aos participantes na segunda parte da coleta de dados, alguns correspondem a jogos. Quando os jogos apareceram, o futebol e videogame foram os mais citados. Entretanto, estes foram mais mencionados pelos homens, apresentando um nível de significância de associação, quando comparados ao gênero feminino, respectivamente de 0,001 e 0,01.

\section{Considerações finais}

Comparando dados desta pesquisa aos encontrados por Rossetti (2001), foi possível perceber indícios de que as preferências por jogos e brincadeiras vão se constituindo paralelamente à construção dos papéis sociais a serem desempenhados na idade adulta. As atividades 
lúdicas preferidas na infância, quanto ao gênero, parecem continuar de certa maneira sendo preferidas na idade adulta. E as relações de maior ou menor estreiteza com as práticas lúdicas também tendem a permanecer.

As transformações socioculturais parecem ter estreita ligação com o atual lugar ocupado pelas atividades lúdicas no mundo. A história indica que o afastamento ou aproximação do adulto das práticas lúdicas variou em razão de mudanças que ocorreram ao longo dos séculos, de maneira que os hábitos e os costumes relacionados à prática lúdica parecem ter acompanhado esse processo histórico (Ariès, 1981).

A condição socioeconômica parece estar ligada a esse processo, na medida em que o mundo do trabalho tem consumido cada vez mais o tempo dos adultos. A falta de recursos econômicos também pode ser um fator importante, visto que nem todas as atividades de lazer estão isentas de algum tipo de custo. E, no caso da realidade brasileira, este pode ser um empecilho bastante relevante.

Quando se faz referência especificamente à condição da mulher em relação às práticas lúdicas, a situação parece ser de um maior afastamento. Vários fatores parecem ter contribuído para esta situação. No caso de algumas atividades esportivas, por exemplo, segundo Lever (1978), alguns fatos históricos, tais como educação e investimento financeiro, acabaram por contribuir para uma participação masculina maior. Além disso, em nossa cultura, estão reservadas à mulher muitas "obrigações", que atualmente não se resumem ao contexto familiar cuidar da casa, filhos e marido. A mulher tem assumido novas funções, e é reconhecida a sua importância na geração de recursos para as despesas familiares. Contudo, parece que algumas situações ainda não foram mudadas, tais como, por exemplo, dispor de tempo "realmente livre" para as chamadas atividades lúdicas.

Parece que, na fase adulta, a tendência de uma estereotipia maior do grupo masculino em comparação com o feminino permanece. É provável que esse fato se deva a uma pressão social menor em face do grupo feminino (Carvalho, Beraldo, Santos \& Ortega, 1993). Essa pressão menor pode estar vinculada à luta feminina por direitos a uma maior "inserção no mundo masculino", o que vem permitindo a visualização da mulher em várias atividades destinadas anteriormente aos homens.

No que diz respeito à escassez de atividades lúdicas no dia-a-dia dos adultos, especialmente os jogos, é bom frisar dois aspectos: primeiramente, é que talvez não haja uma necessidade tão marcada para o divertimento, no caso dos adultos, porque este já ocorre em instâncias tais como o trabalho. Portanto, as atividades lúdicas podem estar diluídas nas atividades cotidianas adultas, de maneira que haveria menor necessidade de períodos marcados e Psico-USF, v. 10, n. 1, p. 77-86, jan./jun. 2005 específicos para este fim, como é o caso das crianças. Em segundo lugar, algumas atividades que aparentemente não seriam lúdicas podem assumir tal característica. É bem diferente cozinhar diariamente, como uma obrigação, de cozinhar esporadicamente, como uma distração (especialmente quando não se tem que limpar toda a sujeira que ficou...). Esse é apenas um exemplo, mas muitas outras atividades podem assumir conotações diferentes, pois "brincar" parece estar vinculado a uma atitude. Portanto, brincar depende de uma postura em relação a um objeto, pessoa ou situação. É necessário estar disponível, sendo esta disposição marcada por um estado físico e psíquico que se manifestará na dinâmica do comportamento lúdico. Brincar ou jogar depende, em última instância, de um ato deliberado de quem brinca ou joga.

Seguindo essa perspectiva, haveria muitas modalidades de atividades lúdicas. No caso dos adultos jovens, a atividade de namorar, por exemplo, também poderia ser pensada desta forma, como um "jogo" que só poderá ser jogado entre parceiros e segundo regras previamente combinadas. Dessa maneira, talvez seja necessária a construção de novas categorias de análise em relação às condutas lúdicas no caso dos adultos, com o objetivo de dar conta de todas as variadas formas que o fenômeno pode assumir nessa faixa etária.

\section{Referências}

Ariès, P. (1981). História social da criança e da família. Rio de Janeiro, RJ: LTC.

Bee, H. (1997). O ciclo vital. Porto Alegre, RS: Artes Médicas.

Bonamigo, L. R. \& Koller, S. H. (1993). Opinião de crianças quanto à influência da estereotipia sexual nos brinquedos. Estudos de Psicologia, 10(2), 21-40.

Campos, L. F. L., Yukumitsu, M. T. C., Fontealba, L. H. \& Bomtempo, E. (1994). Videogame: um estudo sobre as preferências de um grupo de crianças e adolescentes. Estudos de Psicologia, 11(3), 65-72.

Carvalho, A., Beraldo, K., Santos, F. \& Ortega, R. (1993). Brincadeiras de menino, brincadeiras de menina. Psicologia, Ciência e Profissão, 13(1, 2, 3, e 4), 30-33.

Carvalho, A. M. A. (1981). Interação social e brinquedo. Anais da XI Reunião Anual da Sociedade de Psicologia de Ribeirão Preto, Ribeirão Preto, SP.

Denegri, M. \& Linaza, J. L. (s. d.). Los juegos de reglas: estúdio descriptivo de sus manifestaciones em niños urbanos y rurales de la region de la Araucania-Chile. (Manuscrito não-publicado). Madrid: Universidad de la Frontera e Universidad Autônoma de Madrid. 
Dumazedier, J. (1976). Lažer e cultura popular. São Paulo, SP: Perspectiva.

Kirkcaldy, B. (1990). Gender and personality determinants of recreational interests. Studia Psychologica, 32(1-2), 115-121.

Lever, J. (1978). Sex differences in complexity of children's play. American Sociological Review, 43, 471-483.

Maccoby, E. E. (1988). Gender as a social category. Developmental Psychology, 24(6), 755-765.

Macedo, L., Petty, A. L. \& Passos, N. C. (1997). Quatro cores, senha e dominó: oficinas de jogos em uma perspectiva construtivista e psicopedagógica. São Paulo, SP: Casa do Psicólogo.

Melo, V. A. \& Alves Junior, E. D. (2003). Introdução ao lazer. Barueri, SP: Manole.

Mergen, B. (1991). Ninety-five years of historical change in the game preferences of American children. Play \& Culture, 4, 272-283.
Ortega, A. C., Cavarra, C. C., Rosa, L. I., Sacchi, R. A., Abreu, S. N. \& Zanotti, S. V. (1999). Tipificação e estereotipia da preferência lúdica: aspectos psicogenéticos e psicossexuais. (Manuscrito não-publicado). Vitória: ES: Universidade Federal do Espírito Santo.

Rossetti, C. B. (2001). Preferência lúdica e jogos de regras: um estudo com crianças e adolescentes. (Tese de Doutorado). São Paulo, SP: Universidade de São Paulo.

Ruiz, R. O. (1992). El juego infantily la construcción social del conocimiento. Sevilha: Alfar.

Souza, F. (2000). "Menina não entra": um estudo da segregação sexual na interação lúdica de crianças de 8 e 9 anos. (Dissertação de Mestrado). Vitória, ES: Universidade Federal do Espírito Santo.

Recebido em agosto de 2004 Reformulado em maio de 2005 Aprovado em junho de 2005

Sobre as autoras:

Simone Chabudee Pylro é mestre em Psicologia pela Universidade Federal do Espírito Santo e professora da graduação em Psicologia da Unilinhares e da Univix, ES.

Claudia Broetto Rossetti é doutora em Psicologia pela USP e professora da Graduação e da Pós-Graduação em Psicologia da Universidade Federal do Espírito Santo. 